\title{
Геохимия расслоенных интрузий палеопротерозоя Мончегорского рудного района, Кольский регион
}

\author{
Смолькин В.Ф. ${ }^{1}$, Мокрушин А.В. ${ }^{2}$ \\ ${ }^{1}$ Государственный геологический музей им. В.И.Вернадского PAH, Москва, vsmolkin@sgm.ru \\ ${ }^{2}$ Геологический институт КНЦ РАН, Anamumbl, mokrushin@geoksc.apatity.ru
}

Аннотация. Выполнен комплексный геохимический анализ пород рудоносных расслоенных интрузий - Мончеплутона и Имандровского комплекса, массивов габбро-анортозитов комплекса Главного хребта и близких по возрасту дайковых образований палепротерозойского возраста. Полученные результаты, с учетом новых геологических и изотопных данных, позволяют пересмотреть строение и последовательность формирования интрузий, их генетические взаимоотношения и рудный потенциал.

Ключевые слова: Кольский регион, палеопротерозой, расслоенные интрузии, габбро-анортозиты, геохимический анализ.

\section{Geochemistry of the Paleoproterozoic layered intrusions of the Monchegorsk ore area, Kola region}

\author{
Smolkin V.F. ${ }^{1}$, Mokrushin A.V. ${ }^{2}$ \\ ${ }^{1}$ Vernadsky State Geological Museum of Russian Academy of Sciences, Moscow,vsmolkin@sgm.ru \\ ${ }^{2}$ Geological Institute KSC RAS, Apatity, mokrushin@geoksc.apatity.ru
}

\begin{abstract}
A comprehensive geochemical analysis of the rock of the ore-bearing layered intrusions, i.e. the Monchepluton and Imandra complex, gabbro-anorthosite of the Main Ridge complex and close by age paleoproterozoic dyke formations has been performed. The results obtained, in view of the new geological and isotope data, allow us to revise the structure and sequence of the intrusions formation, their genetic relationships and ore potential.

Key words: The Kola region, the Paleoproterozoic, layered intrusions, gabbro-anorthosites, geochemical analysis.

\section{Введение}

Мончегорский рудный район, расположенный в центральной части Кольского региона, является уникальным полигоном для изучения расслоенных интрузий палеопротерозойского возраста. Это обусловлено расположением на его территории расслоенных интрузий базит-ультрабазитового состава двух возрастных групп (2.5 и 2.45 млрд. лет), одновозрастных комагматических даек и массивов габбро-анортозитов, а также наличием разнообразных месторождений и рудопроявлений сульфидных Cu-Ni-PGE, малосульфидных платинометалльных, хромитовых и титаномагнетитовых руд, хорошей обнаженностью и доступностью территории (Расслоенные..., 2004).

Большой объем изотопных исследований U-Pb (TIMS, SIMS), Sm-Nd и Re-Os систем, полученных начиная с 90-ых годов до настоящего времени, позволил определить возраст, длительность и последовательность их формирования (Смолькин, 2017). Однако вопрос о их генетических взаимоотношений остается открытым. Одним из методов решения этого вопроса является геохимический анализ пород, слагающих расслоенные интрузии.
\end{abstract}

\section{Объекты}

Для анализа были выбраны расслоенные интрузии обеих возрастных групп, комплекс габброанортозитов Главного хребта и дайки. Первая группа представлена Мончеплутоном (2507-2496 млн. лет), включая породы предгорья Вурэчуайвенч, Нюд-II, габбро 10 аномалии. Их внедрение в начале палеопротерозоя и последующая ледниковая эрозия в период гуронского оледенения предшествовали заложению крупнейшего Печенгско-Варзугского палеорифтогенного пояса (Smolkin, 1997). Ко второй группе относятся массивы Прихибинский, Умбареченский и Большая Варака Имандровско-

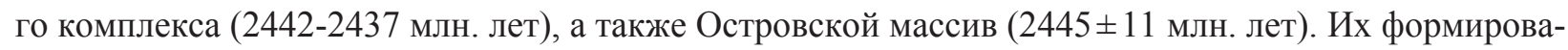


ние происходило позднее, в рифтогенных условиях на фоне интенсивного базальтового и среднекислого вулканизма.

Комплекс габбро-анортозитов Главного хребта представлен массивами Мончетундры (2521-2467 млн. лет) и Чуна- и Волчьих тундр (2473-2463 млн. лет), которые разделены крупными разломами в период 1.9 млрд. лет. Изучены дайки и пластовые тела гарризитов, прорывающее породы Мончетундры, габброноритовая дайка (Оленегорская, $2491 \pm 4$ млн. лет) и дайки габбро, норита, феррогаббро и микрогранита, секущие породы Дунитового блока (2496 14 млн. лет) и Лойпиш-

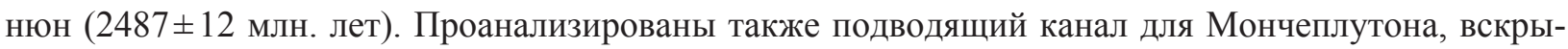
тый скв. М-1 (инт. 2037-2387 м), вмещающие породы (гнейсы, диориты, роговики, бластокатаклазиты), жилы гранофиров, а также глубинные ксенолиты из кимберлитов.

\section{Методы анализа и схема обработки данных}

Для выполнения исследований был создан Банк современных данных, включающий анализы породобразующих элементов методом Emission-ICD, рудных, редких и редкоземельных элементов методом ICP-MS. Основная их часть была получена в Национальном центре научных исследований Франции (г. Нанси) в рамках проекта РФФИ-CNRS. Дополнительно были использованы данные (Криволуцкая и др., 2010; Нерович и др., 2009, Чащин и др., 2012; Groshev et al., 2018; Sharkov, Chistyakov, 2012).

Схема обработки данных включала построение диаграмм для породообразующих компонентов $\mathrm{SiO}_{2}, \mathrm{TiO}_{2}, \mathrm{Al}_{2} \mathrm{O}_{3}, \mathrm{Fe}_{2} \mathrm{O}_{3}$ tot., $\mathrm{CaO}, \mathrm{Na}_{2} \mathrm{O}_{3}+\mathrm{K}_{2} \mathrm{O}, \mathrm{P}_{2} \mathrm{O}_{5}$ относительно $\mathrm{MgO}$; для рудных элементов $\mathrm{Ni}-\mathrm{Cu}, \mathrm{Ni}-\mathrm{Cr}, \mathrm{Ni} / \mathrm{Cu}-\mathrm{MgO}, \mathrm{Ni} / \mathrm{Co}-f$ порода, $\mathrm{Ni} / \mathrm{Cu}-\mathrm{S}$; для анализа соотношения когерентный/ некогерентный элементы $\mathrm{La} / \mathrm{Yb}-\mathrm{TiO}_{2}, \mathrm{Th} / \mathrm{Yb}-\mathrm{Nb} / \mathrm{Yb}, \mathrm{Th} / \mathrm{Nb}-\mathrm{La} / \mathrm{Yb}, \mathrm{La} / \mathrm{Sm}-\mathrm{Gd} / \mathrm{Lu}$; а также спектров РЗЭ, нормированных к хондриту и спайдер-диаграмм содержаний редких элементов, нормированных к деплетированной мантии (DM). Диаграммы строились с учетом особенностей формирования и строения интрузий: для Мончеплутона были выделены 5 мегаритмов, обусловленных фазным внедрением магм; в строении разрезов Мончетундры и Имандровского комплекса - по три главных зон (Расслоенные..., 2004; Смолькин, 2017); породы Чуна- и Волчьих тундр представлены раздельно.

\section{Результаты геохилического анализа}

Мончеплутон. Слагающие его породы образуют два четко выраженных тренда. Первый включает в себя дуниты-гарцбургиты-ортопироксениты I, II и III мегациклов, для которых устанавливается значительное повышение содержания $\mathrm{SiO}_{2}$ по мере снижения $\mathrm{MgO}$ и низкие нормированные содержания РЗЭ, что обусловлено кристаллизацией под оливиновым контролем. Второй тренд - это нориты-габбронориты-анортозиты IV и V мегациклов с значительным увеличением содержания $\mathrm{Al}_{2} \mathrm{O}_{3}, \mathrm{CaO}$ при относительно стабильном $\mathrm{SiO}_{2}$ по мере уменьшения $\mathrm{MgO}$. Составы пород обоих трендов значительно перекрываются по содержанию $\mathrm{Fe}_{2} \mathrm{O}_{3}$ tot и летучих $-\mathrm{P}_{2} \mathrm{O}_{5}$.

Породы I и II мегациклов отличаются повышенным содержанием $\mathrm{Cr}$, а III мегацикла - Ni и высоким отношением Ni/Co. Метагаббро 10 аномалии близки по содержанию большинства породообразующих компонентов и спектрам РЗЭ к породам V мегацикла, отличаясь высоким содержанием $\mathrm{TiO}_{2}$ и низким - Ni.

Для всех пород характерным является плоский характер нормированных спектров РЗЭ с небольшим увеличением содержания ЛР3Э (рис. 1), положительная $\mathrm{Sr}$ и отрицательная $\mathrm{Nb}-\mathrm{Ta}$ аномалии на спайдер-диаграммах. Состав исходной магмы по большинству параметров, за исключением низкого содержания $\mathrm{P}_{2} \mathrm{O}_{5}$, отвечает составу оливинового габбронорита придонной зоны г. Травяная. Комагматические дайки габброноритов, секущие породы Мончеплутона и расположенные вне его, различаются по $\mathrm{MgO}$ и $\mathrm{Al}_{2} \mathrm{O}_{3}$, но близки по спектрам РЗЭ. По своим геохимическим особенностям они близки к породам IV мегацикла.

Монче-, Чуна- и Волчьи тундры. Породы нижней зоны Мончетундры, преимущественно представленные меланоноритами, ортопироксенитами и плагиогарцбургитами, существенно отличаются от пород средней и верхней зон более высоким содержанием $\mathrm{MgO}, \mathrm{Cr}$ и низким - $\mathrm{Al}_{2} \mathrm{O}_{3}, \mathrm{CaO}$, 

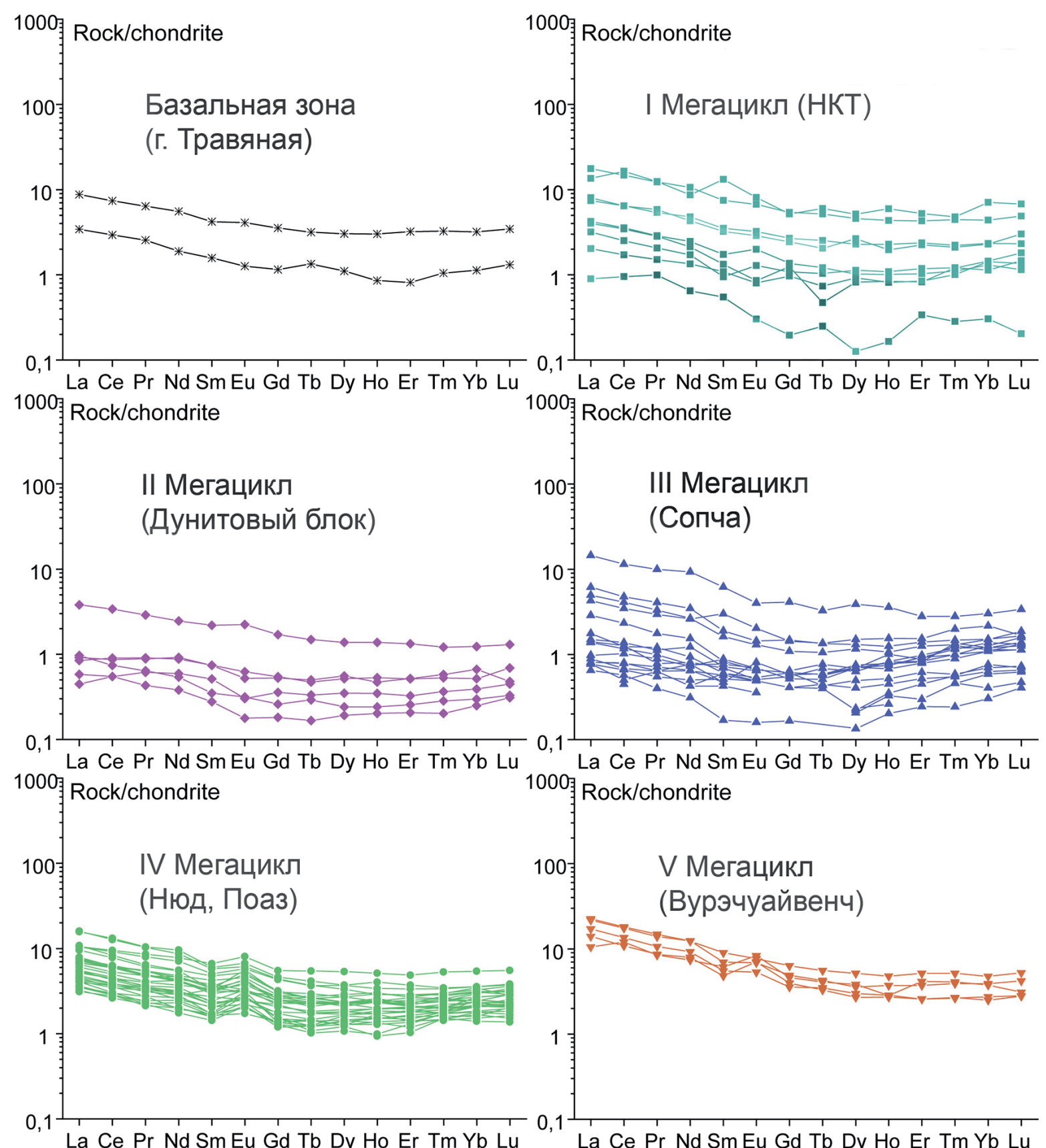

La Ce Pr Nd SmEu Gd Tb Dy Ho Er Tm Yb Lu 1000: Rock/chondrite
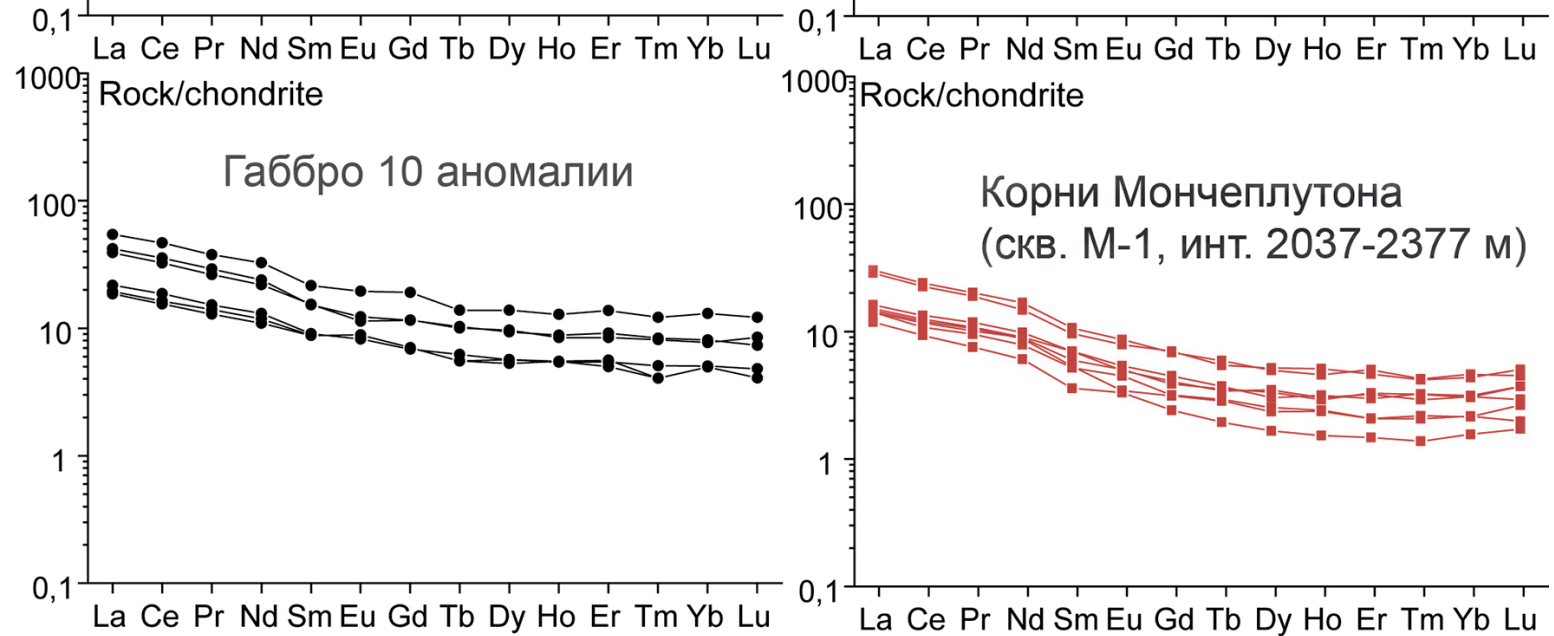

Рис. 1. Распределение РЗЭ в породах Мончеплутона, нормированное к хондриту по (McDonough, Sun, 1995).

Fig. 1. REE distribution in rocks of the Monchepluton, chondrite-normalized after (McDonough, Sun, 1995). 
Р3Э. Они сопоставимы по большинству параметров, включая спектры Р3Э, с породами IV мегацикла Мончеплутона.

Составы пород средней и верхней зон Мончетундры в значительной степени перекрываются. Породы Чуна- и Волчьих тундр, максимально обедненные $\mathrm{MgO}, \mathrm{Fe}_{2} \mathrm{O}_{3}$ tot, но обогащенные $\mathrm{Al}_{2} \mathrm{O}_{3}$, $\mathrm{Na}_{2} \mathrm{O}_{3}+\mathrm{K}_{2} \mathrm{O}$, завершают тренд пород средней и верхней зон.

Для пород Мончетундры характерным является однотипный плоский характер распределения спектров РЗЭ и слабо выраженная положительная Еu аномалия, для пород Чуна- и Волчьих тундр - обогащение ЛРЗЭ и сильно выраженная положительная Еu аномалия (рис. 2). Судя по спайдердиаграммам, для пород Мончетундры и Чунатундры, как и для пород Мончетундры, установлены положительная $\mathrm{Sr}$ и отрицательная $\mathrm{Nb}-\mathrm{Ta}$ аномалии.

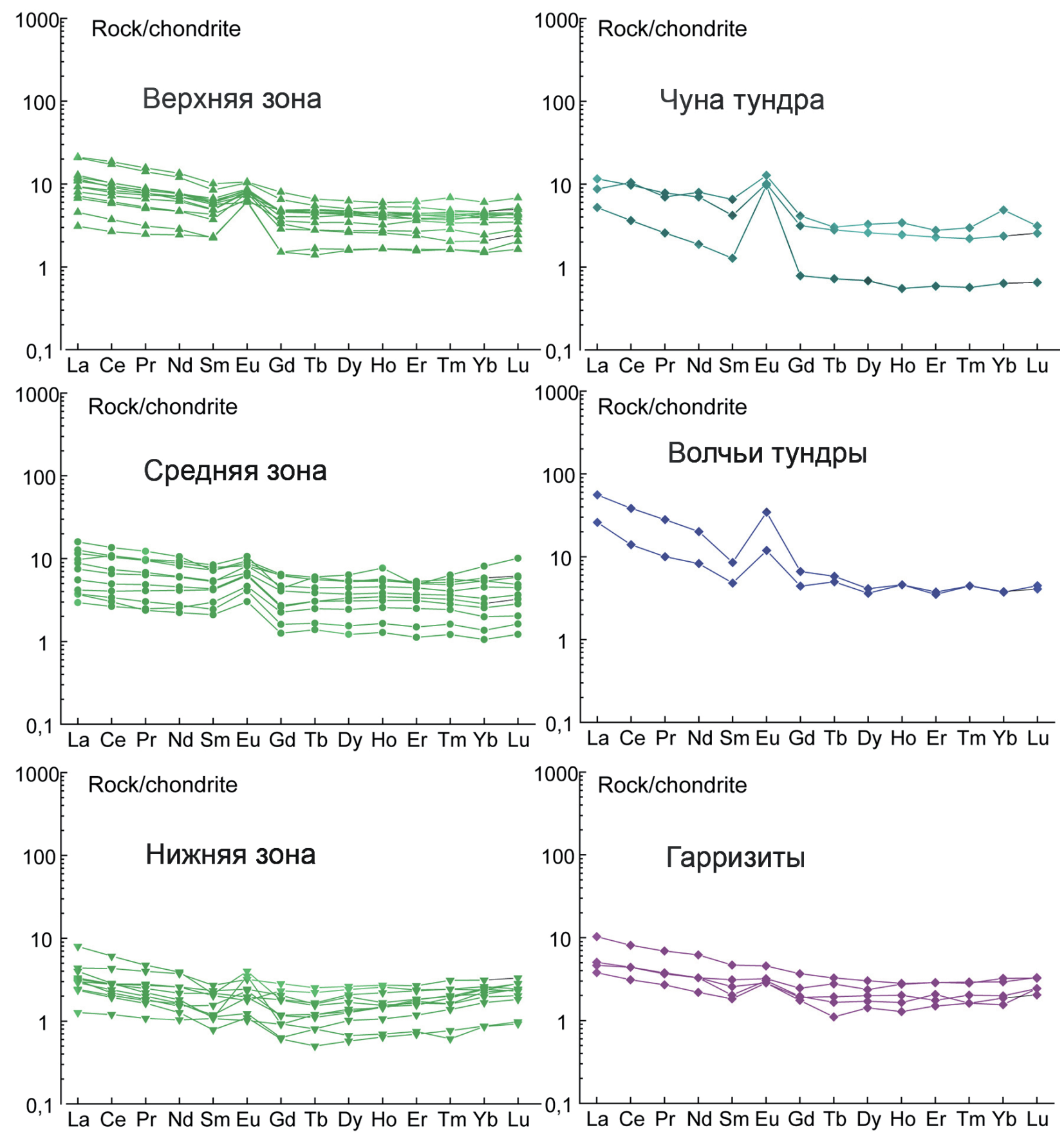

Рис. 2. Распределение РЗЭ в породах Монче-, Чуна- и Волчьих тундр, нормированное к хондриту.

Fig. 2. REE distribution in the rocks of the Monche-Chuna-Wolf tundra, chondrite-normalized. 
Ультрабазиты подводящего канала, вскрытого скв. М-1, по своим геохимическим, а также минералогическим особенностям, значимо отличаются от пород Мончетундры, что подтверждает независимость их образования. Дайки и пластовые тела гарризитов, прорывающие габброиды верхней зоны Мончетундры, не имеют аналогов среди магматических образований района и обладают специфическими особенностями - высоким содержанием $\mathrm{Fe}_{2} \mathrm{O}_{3}$ tot (18-21 мас. \%), повышенным - Ni и низким $\mathrm{P}_{2} \mathrm{O}_{5}$.

Имандровский комплекс и Островской массив. Породы Имандровского комплекса не образуют единый тренд и разделяются на 2 кластера. Первый кластер включает породы Нижней расслоенной зоны (Большая Варака, Умбареченский) с повышенным содержанием $\mathrm{MgO}$, $\mathrm{Ni}$ и Cr; второй кластер - породы Главной и Верхней расслоенных зон (Прихибинский) с повышенным содержанием $\mathrm{Al}_{2} \mathrm{O}_{3}$ и СаО. Специфичными являются породы Прикровельной зоны с высокими содержаниями $\mathrm{TiO}_{2}$ и $\mathrm{Fe}_{2} \mathrm{O}_{3}$ tot, и гранофиры с высокими содержаниями $\mathrm{SiO}_{2}, \mathrm{~K}_{2} \mathrm{O}$ и повышенными $-\mathrm{P}_{2} \mathrm{O}_{5}$.

Породы Островского массива наиболее близки к породам 2 кластера, в том числе по спектрам Р3Э, отличаясь более высокими содержаниями Ni и низкими - Cr. Для пород Имандровского комплекса и Островского массива установлены повышенное общее содержание РЗЭ и относительное обогащение ЛРЗЭ по сравнению с породами Мончеплутона, отрицательная $\mathrm{Nb}-\mathrm{Ta} \mathrm{и} \mathrm{положительная}$ $\mathrm{Sr}$ аномалии, а также отсутствие Еu аномалии (рис. 3 a, б).
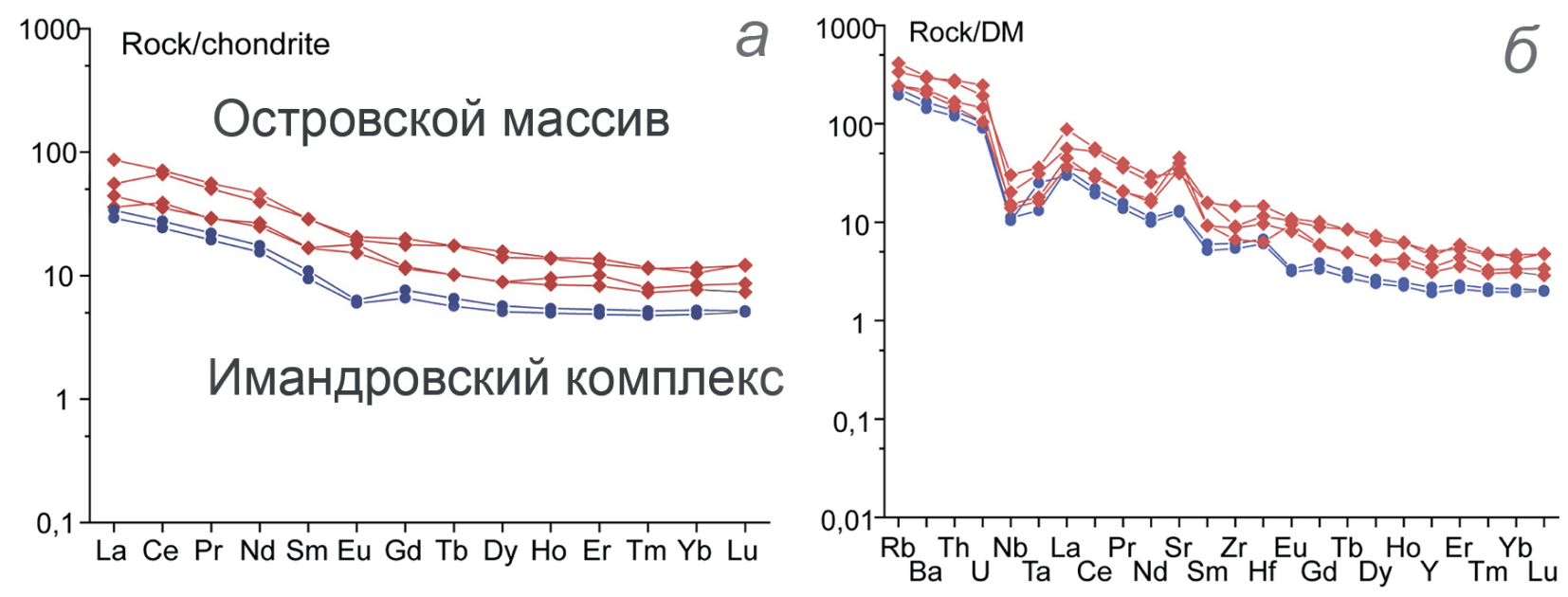

Рис. 3. Спектр РЗЭ в породах Имандровского комплекса и Островского массива (a), и спайдер-диаграмма (б), нормированная к DM по (Salters, Stracke, 2005).

Fig. 3. The spectrum of REE in the rocks of the Imandra complex and Ostrovsky array (a), and spider-diagram (б) normalized to DM after (Salters, Stracke, 2005).

\section{Заключение}

Расслоенные интрузии и массивы габбро-анортозитов, геологические взаимоотношения между которыми имеют сложный характер, обнаруживают генетическую связь, что выражается в сходстве состава отдельных зон. Это является одним из оснований для пересмотра истории их формирования.

Изученные магматические образования могут рассматриваться как производные плюма, расположенного в пределах нижней коры и эволюционирующего в течении 2.5-2.4 млрд. лет. Их разнообразие обусловлено степенью плавления первичного мантийного субстрата, характером и степенью контаминации магм веществом нижней коры, эволюцией магм в глубинных промежуточных очагах, пульсационным характером подъема и внедрения магм в верхнюю кору, дифференциацией магм в пределах магматической камеры, которая контролируется снижением температуры, флюидным режимом и окислительным потенциалом. 
На основе геохимического анализа интрузивных пород Мончегорского рудного района с учетом ранее полученных геологических и изотопных данных сделаны следующие выводы:

1. Первичные мантийные магмы, глубинные очаги которых находились в пределах нижней коры, испытали в различной степени коровую контаминацию. Об этом свидетельствует Nb-Ta аномалия, относительная обогащенность ЛРЗЭ, а также отрицательные значения первичного отношения $\varepsilon_{\mathrm{Nd}}$.

2. Расслоенные интрузии и массивы габбро-анортозитов, геологические взаимоотношения между которыми имеют сложный характер, обнаруживают генетическую связь, что выражается в сходстве состава отдельных зон. Это является одним из оснований для пересмотра истории их формирования.

3. Для массивов комплекса Главного хребта характерным является положительная Еu аномалия, отсутствующая в породах Мончеплутона. Значение ее возрастет от пород Мончетундры к Чуна- и Волчьим тундрам, что обусловлено увеличением степени фракционирования и накопления плагиоклаза по мере продвижения магмы в южном направлении.

4. Формирование Мончеплутона сопровождалось термическим выплавление жил микрогранитов из вмещающих пород архейского возраста; внедрение массивов Имандровского комплекса привело к активному взаимодействию магмы с участие флюидов с перекрывающими кислыми вулканитами с образованием гранофиров.

5. Имандровский комплекс и Островской массив обнаруживают значительное геохимическое сходство пород. Поэтому они могут быть объединены в один комплекс, что согласуется с их близким U-Рb возрастом.

Работа выполнена при поддержке Программы фундаментальных исследований ОНЗ РАН №2 и темы НИР ГИ КНЦ РАН № 0226-2019-0053.

\section{Литература}

1. Криволуцкая Н.А., Смолькин В.Ф., Свирская Н.М., Мамонтов В.П., Фаныгин А.С., Беляцкий Б.В., Рощина И.А. Геохимические особенности массивов друзитового комплекса центральной части Беломорского подвижного пояса: 1. Распределение главных и редких элементов в породах // Геохимия. 2010. № 3. С. 16-44.

2. Нерович Л.И., Баянова Т.Б., Савченко Е.Э., Серов П.А., Екимова Н.А. Новые данные по геологии, петрографии, изотопной геохимии и ЭПГ минерализации Мончетундровского массива // Вестник МГТУ. Т. 12. № 3. 2009. С. 461-477.

3. Расслоенные интрузии Мончегорского рудного района: петрология, оруденение, изотопия, глубинное строение. Ф.П. Митрофанов, В.Ф. Смолькин (ред.). Апатиты. Изд-во: КНЦ РАН. 2004. 367 с.

4. Смолькин В.Ф. Рудоносные расслоенные интрузии базит-ультрабазитов палеопротерозоя восточной части Балтийского щита: проблемы длительности и фазности их формирования // Тезисы Всерос. конф. «Основные проблемы в учении об эндогенных рудных месторождениях: новые горизонты». М. Изд-во: ИГЕМ РАН. 2017. С. 461-464.

5. Чащин В.В., Баянова Т.Б., Елизарова И.Р., Серов П.А. Волчьетундровский массив комплекса автономных анортозитов Главного хребта, Кольский полуостров: геологические, петрохимические и изотопногеохронологические исследования // Петрология. 2012. Т. 20. С. 514-540.

6. Groshev N.,Yu., Pripachkin P.V., Karykowski B.T., Malygina A.V., Rodionov B.V., Belyatsky B.V. Genesis of a Magnetite Layer in the Gabbro-10 Intrusion, Monchegorsk Complex, Kola Region: U-Pb SHRIMP-II Dating of Metadiorites // Geology of Ore Deposits. 2018. V. 60. № 6. P. 486-496.

7. McDonough W.F., Sun S.S. The composition of the Earth // Chem. Geol. 1995. V. 120. P. 223-253.

8. Salters U.J.M., Stracke A. Composition of the depleted mantle. Geochemistry, Geophysics, Geosystems // An electronic Journal of the Earth Sciences. 2004. V. 5. № 5. P. 1-27.

9. Sharkov E.V., Chistyakov A.V. The Early Paleoproterozoic Monchegorsk Layered Mafite-Ultramafite Massif in the Kola Peninsula: Geology, Petrology, and Ore Potential // Petrology. 2012. V. 20. № 7. P. 607-639.

10. Smolkin V.F. The Paleoproterozoic (2.5-1.7 Ga) midcontinent rift system of the northeastern Fennoscandian Shield // Can. J. Earth Sci. Spesial Publ. 1997. V. 34. P. 426-443. 